\section{Nachruf Dr. Reinhard Schulz}

Am I. Mai 2018 starb im 83. Lebensjahr Dr. Reinhard Schulz. Er war einer der Pioniere der pädiatrischen Ultraschalldiagnostik. Ich lernte ihn 1975 bei einer Hospitation in Mainz kennen und schätzen. Es war insofern ein ungewöhnliches Aufeinandertreffen, weil er bereits ein erfahrener Kinderradiologe war, ich hingegen Assistent im zweiten Facharztjahr. Uns verband die Leidenschaft für den Ultraschall und das gemeinsame Bemühen, diese risikolose, kinderfreundliche Methode trotz der damals noch völlig unbekannten Schnittbild-Anatomie im Kollegenkreis bekannt zu machen.

Bei Ultraschall-Kongressen trafen wir uns in den 70er Jahren dann meistens in Sitzungen mit anderen kleineren Fachgebieten wieder, da das Interesse der eigenen Fachgruppen (Pädiater, Kinderchirurgen und Kinderradiologen) sehr gering war. Erst 1983 gründeten wir eine eigene Sektion in der DEGUM und gaben zusammen mit den Teilnehmern des ersten Ausbilder-Seminars Ausbildungsempfehlungen heraus. Sie erschienen in einem damals viel beachteten Nestle-Heft, 1990 in dritter Auflage letztmalig publiziert.
Die wachsende Bedeutung des Ultraschalls zeigte sich bei der von Reinhard Schulz 1983 veranstalteten 20. Jahrestagung der Gesellschaft für pädiatrische Radiologie: Fast die Hälfte der Vorträge waren der Ultraschalldiagnostik gewidmet. Um dem großen Ausbildungsbedarf nachzukommen, führte er in den Folgejahren mit vorbildlichem Engagement im Olga-Hospital Stuttgart Ultraschallkurse durch. Mehr als 1500 Pädiater und Kinderradiologen haben durch ihn das Rüstzeug für die Ultraschalldiagnostik erhalten. Zudem gab er einer stattlichen Anzahl von in- und ausländischen Kollegen die Gelegenheit bei ihm zu hospitieren.

Die unglaubliche Geschwindigkeit, mit der sich die Ultraschalldiagnostik in den 80er Jahren entwickelte, spiegelt sich wider in dem von ihm und Ulrich V. Willi 1989 beim Thieme-Verlag herausgegebenen „Atlas der Ultraschalldiagnostik beim Kind“.

Ausgleich fand Reinhard Schulz im Querflötenspiel - und das nicht nur im stillen Kämmerlein, sondern auch beispielsweise im Kinderärzteorchester. Auch in dieser

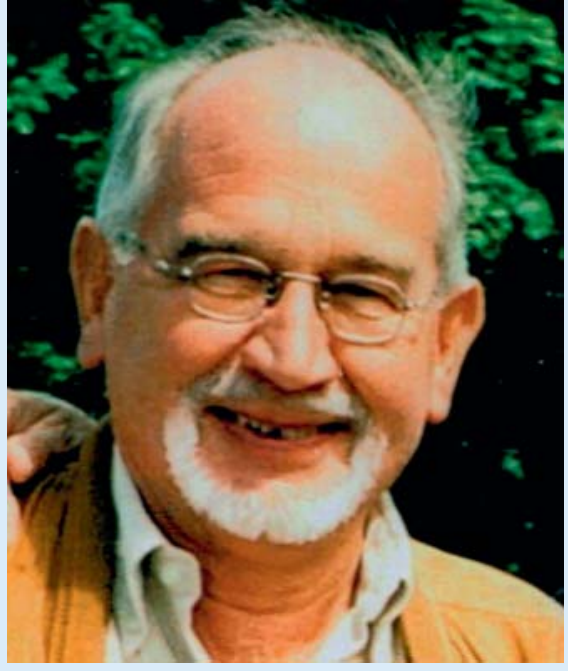

Dr. Reinhard Schulz

Hinsicht wird er vielen in Erinnerung bleiben.

Prof. Dr. med. Dieter Weitzel 